\title{
O CURRÍCULO DA EDUCAÇÃO FÍSICA NA REDE MUNICIPAL DE BARUERI: AS PERCEPÇÕES DOS PROFESSORES
}

\author{
THE PHYSICAL EDUCATION CURRICULUM IN BARUERI'S MUNICIPAL \\ SCHOOLS: TEACHERS' PERCEPTIONS
}

\section{EL CURRÍCULO DE EDUCACIÓN FÍSICA EN LA RED MUNICIPAL DE BARUERI: PERCEPCIONES DE LOS DOCENTES}

Lidiane Marani*, Luiz Sanches Neto**, Elisabete dos Santos Freire*

\begin{abstract}
Palavras chave:
Educação Física

e Treinamento.

Educação.

Currículo.

Docentes.

Resumo: 0 objetivo deste estudo foi conhecer as percepções dos professores de Educação Física do município de Barueri/SP sobre o plano de referência do componente curricular e sua implementação. Foi realizada uma pesquisa qualitativa e 14 professores foram entrevistados, sendo analisado o conteúdo dessas entrevistas. Foi possível compreender que os professores são favoráveis à existência do currículo comum que uniformiza a prática pedagógica, mas anseiam por alguma flexibilidade para adequá-lo às suas concepções e às características dos estudantes. Eles criticam a concepção, a organização dos conteúdos e, principalmente, a implementação do currículo. Tensões e conflitos na construção curricular foram identificados, assim como a interdependência entre as dimensões do currículo. Assim, transforma-se o professor pela interferência do currículo oficial e transforma-se o currículo pela ação do professor.
\end{abstract}

Keywords: Physical Education and Training.

Education.

Curriculum.

Faculty.

Palabras clave: Educación Física y Entrenamiento. Educación. Currículo. Docentes. its implementation process. Qualitative research was conducted including interviews with
Abstract: This study aimed to know physical education teachers' perceptions in the city of Barueri, São Paulo, about the reference plan for the PE curricular component and on fourteen teachers, which were the focus of content analysis. It found that teachers favor a common curriculum that standardizes pedagogical practice, but they want some flexibility to adapt it to their views and to students' characteristics. Teachers criticize the curriculum's design, content organization and especially implementation. Tensions and conflicts were found in curriculum development as well as interdependence between curriculum dimensions. Thus, teachers are changed by interference of the official curriculum and the curriculum is changed by teachers' action.

Resumen: El objetivo de este estudio es conocer las percepciones de los profesores de Educación Física en el municipio de Barueri (Estado de São Paulo) acerca del plan de referencia para el componente curricular y su implementación. En una investigación cualitativa, 14 profesores fueron entrevistados y se analizó el contenido de esas entrevistas. Fue posible entender que los docentes son favorables a la existencia de un currículo común que uniformice la práctica pedagógica, pero desean una cierta flexibilidad para adaptarlo a sus concepciones y a las características de los estudiantes. Los profesores critican el diseño, la organización de contenidos y, sobre todo, la implementación del currículo. Tensiones y conflictos en la construcción curricular han sido identificados, así como la interdependencia entre las dimensiones del currículo. Así, se transforma el profesor por la interferencia del currículo oficial y el currículo se transforma por la acción del profesor.
*Universidade São Judas Tadeu. São Paulo, SP, Brasil.

E-mail: lidimarani@gmail.com

**Universidade Federal do Ceará. Fortaleza, CE, Brasil. E-mail: luizitosanches@yahoo.com

Recebido em: 06-06-2016 Aprovado em: 30-11-2016

(c) (1) (8) Licence 


\section{INTRODUÇÃOO}

A política educacional brasileira estabelecida nas últimas décadas tem estimulado municípios e estados a construir suas propostas curriculares comuns. Essas propostas, oficialmente determinadas e expressas em documentos legais, caracterizam o chamado currículo oficial (SACRISTÁN, 2013). Galian (2014) explica que a elaboração de propostas curriculares oficiais tem sido intensificada após aprovação da Lei de Diretrizes e Bases da Educação Nacional - LDB (BRASIL, 1996) e dos Parâmetros Curriculares Nacionais - PCN (BRASIL, 1997). Sampaio (2010) confirma as afirmações de Galian (2014) e analisa 60 propostas curriculares de diferentes unidades da federação, identificando o impacto dos PCN em suas formulações.

Como consequência dessa conjuntura, observamos o surgimento de inúmeras propostas curriculares específicas para a Educação Física. Treze delas, adotadas em diferentes unidades da federação, foram identificadas por Tenório (2012). Em São Paulo, a Secretaria de Estado da Educação adotou a Proposta Pedagógica Curricular (SÃO PAULO, 2008), definindo um currículo comum para as escolas da rede. Diversos municípios paulistas também têm implementado currículos comuns, como a Prefeitura do Município de São Paulo, que publicou suas "Orientações Curriculares e Proposição de Expectativas de Aprendizagem para a Educação Física" (SÃO PAULO, 2007).

A política educacional adotada tem colocado a Educação Física diante de uma nova realidade. Até há bem pouco tempo, a organização curricular da área era responsabilidade exclusiva e individual do professor, que raramente tinha acesso a um currículo oficial ou a um "currículo nacional disfarçado" (APPLE, 1994, p.63), apresentado em livros didáticos. Atualmente, além da existência de propostas oficiais, algumas redes de ensino adotam um material apostilado para professores e alunos. Conhecer a percepção dos professores sobre o impacto desta nova política educacional tem atraído a atenção de pesquisadores da Educação Física, como Seixas (2011), Branquinho (2011), Lagoeiro (2012), Marques (2014), Tenório (2012) e Barros (2014). Nessas pesquisas, os autores identificaram a existência de diferentes percepções.

Assim, há professores que consideram negativa a adoção de um currículo oficial, por entenderem que ele desrespeita as necessidades dos estudantes e limita a autonomia do professor, já que não há flexibilidade para a organização dos conteúdos (BRANQUINHO, 2011; FREITAS, 2011). Outros problemas identificados pelos professores foram a resistência dos estudantes (SEIXAS, 2011; ARRUDA, 2014), a falta de incentivo dos sistemas de ensino à formação continuada (LAGOEIRO, 2012; MARQUES, 2014, TENÓRIO, 2012) e a escassez de recursos materiais e infraestrutura para a realização das aulas (SEIXAS, 2011; MALDONADO, 2012; ARRUDA, 2014; BARROS, 2014; MARQUES, 2014).

Por outro lado, alguns professores argumentam que a existência de uma proposta curricular única é positiva, pois apresenta uma orientação comum para todos os docentes de uma mesma rede de ensino (SEIXAS, 2011; TENÓRIO, 2012; ROCHA, 2014), estimula a busca por novos conhecimentos para melhorar sua prática pedagógica e incentiva a inclusão de novas temáticas nas aulas (GUNTHER, 2006; BARROS, 2014). Para esses professores, as transformações produzidas com a nova organização curricular podem contribuir para a valorização da Educação Física na escola. Nesse sentido, mudanças positivas no comportamento dos estudantes têm sido percebidas (FREITAS, 2011). 
Grande parte dos estudos encontrados tem focalizado as percepções de professores sobre o currículo da rede estadual de São Paulo (SÃO PAULO, 2008), como Freitas (2011), Seixas (2011) e Lagoeiro (2012). Este currículo possui características próprias de elaboração, concepção e forma de implementação, que podem ter influência sobre a percepção dos professores. Esta proposta, implantada em 2008 , foi formulada por uma equipe de especialistas da área, sem a colaboração dos professores da rede (NOVAES, 2009), o que tem gerado algumas críticas (CASTELLANI, 2013; BRANQUINHO, 2011).

Um processo diferente foi adotado por outras redes de ensino, que estimularam a participação de seus professores na construção do currículo. Tenório (2012) explica que, por vezes, o currículo implementado foi resultado do diálogo entre consultores convidados e professores. Em outros casos, os professores da rede foram os únicos responsáveis pelo currículo apresentado, como em Barueri, município da Grande São Paulo. Em 2010 a Secretaria Municipal de Educação da cidade implantou um currículo oficial para a área, denominado Plano de Referência de Educação Física - PR (BARUERI, 2015). Sua primeira versão entrou em vigor no ano de 2010 e foi concebida por alguns professores da própria rede, convidados pelos gestores. Outra equipe foi constituída para realizar uma reformulação deste plano, em 2014. Nesse momento, todos os professores foram convidados a debater os objetivos e conteúdos propostos.

Como explica Freitas (2011), alguns autores argumentam que a contribuição dos professores na construção da proposta curricular pode influenciar a forma como eles recebem, percebem e implementam esta proposta. Para a autora, a não adoção ao currículo oficial tem sido atribuída à falta de oportunidade para que o professor se manifeste sobre as determinações a ele impostas. Contudo, ela argumenta que essa relação entre participação e adoção pode não ser tão direta e, portanto, merece ser investigada.

Entendemos que as percepções do professor sobre o currículo oficial influenciam a forma como ele elabora o currículo real, definido por Sacristán $(2013$, p. 26) como aquele que se concretiza na escola, que é "realizado em práticas, com sujeitos concretos e inserido em um contexto". Nessa perspectiva, conhecer as percepções dos professores de diferentes redes de ensino nos permitirá conhecer os fatores que influenciam sua interpretação e como as características e formas de implantação de cada proposta podem impactar a realidade da Educação Física.

Como afirma Sacristán (2000), a construção do currículo se dá a partir de um complexo processo, permeado por conflitos. Se, por um lado, o currículo oficial pode ser um instrumento de controle do trabalho docente, é preciso reconhecer que o professor é sempre um mediador desse currículo e pode, também, gravar nele suas próprias concepções, especialmente quando ele o participa de sua elaboração. Assim, concordando com o autor, acreditamos que "[...] 0 currículo molda os docentes, mas é traduzido na prática por eles mesmos - a influência é recíproca" (SACRISTÁN, 2000, p. 165).

Partindo desta premissa, na tentativa de contribuir para a compreensão sobre a ação do professor na complexa e conflituosa construção curricular, elaboramos o presente estudo com o objetivo de conhecer as percepções dos professores de Educação Física do município de Barueri sobre o Plano de Referência da área e sobre sua implementação. 


\section{METODOLOGIA}

Para acessar as informações necessárias para este estudo, optamos por realizar uma investigação de natureza qualitativa, nos aproximando do contexto escolar para conhecer as percepções dos professores sobre suas experiências e sua realidade (GODOY, 1995). Nossa intenção foi conhecer, descrever e interpretar esta realidade, a partir da perspectiva dos professores.

Antes de iniciar o contato com os participantes, o responsável pela Secretaria de Educação do município foi informado sobre a pesquisa e autorizou sua realização. Em seguida, os diretores das escolas foram procurados e, com seu consentimento, entramos em contato com os professores para informá-los e realizar o convite para a pesquisa. Os convites foram realizados nas próprias escolas, sendo que 14 professores que aceitaram participar do estudo e registraram sua autorização no Termo de Consentimento Livre e Esclarecido. Para manter o sigilo dos participantes, optamos por identificá-los no estudo por nomes fictícios, escolhidos por eles mesmos. Os procedimentos de pesquisa foram submetidos a Comitê de Ética em Pesquisa, conforme processo CAAE no. 39690414.8.0000.0089.

Participaram do estudo 14 professores, sendo oito do sexo masculino e seis do feminino. A idade variou entre 27 e 63 anos. Três deles têm menos de 30 anos de idade, sete têm entre 31 e 40 anos, três têm entre 41 e 50 e uma tem mais de 51 anos. Apenas um dos participantes tem menos de cinco anos de formação na área. Metade dos participantes tem entre seis e dez anos de formação, três têm entre 11 e 20 anos e outros três concluíram seus cursos há mais de 20 anos. Todos estão em efetivo exercício na rede municipal de Barueri, há pelo menos 18 meses, tempo de atuação de dois participantes. Cinco têm entre três e nove anos de atuação e seis têm entre dez e 15 anos. Quanto ao nível de ensino atendido, identificamos que todos atuam no Ensino Fundamental e cumprem uma carga horária semanal que varia entre 12 e 26 horas-aula. Contudo, dez professores estão comprometidos com uma carga horária maior, pois trabalham também em outras redes de ensino ou em outra escola do município de Barueri.

Para conhecer as percepções dos professores sobre o PR, optamos por utilizar a entrevista semiestruturada (BOGDAN; BIKLEN, 2003). Assim, procuramos estimular 0 participante a apresentar seus argumentos de forma aprofundada, permitindo a identificação de possíveis conflitos ou contradições (KVALE, 2007). Concordando com Brinkmann (2007), acreditamos que a entrevista deve ter um caráter dialógico, no qual pesquisador e participante produzam conhecimento conjuntamente. Todas as entrevistas ocorreram na escola onde os participantes trabalham e sua duração variou entre 19 e 52 minutos. Cada entrevista foi gravada e transcrita para facilitar sua análise. Um caderno de campo foi constituído para registrar as impressões e observações do pesquisador sobre a realização da entrevista.

A Análise de Conteúdo Temática, apresentada em Campos (2004) e Braun e Clarke (2006), foi utilizada para interpretar os relatos dos participantes. Seguindo as orientações dos autores, a análise foi organizada em etapas. Na primeira delas houve a familiarização com o material, que teve início durante a entrevista e sua transcrição, tendo continuidade com a realização da "leitura flutuante", que possibilitou o primeiro levantamento das ideias principais e seus significados. A segunda etapa consistiu na seleção de unidades de significados e identificação de temas. Como sugerem Braun e Clarke (2006), nesta etapa foram construídos 
mapas que permitiram visualizar possíveis temas, reorganizados na terceira etapa, dando origem aos temas ou categorias. Durante esta análise, o Plano de Referência para a Educação Física foi consultado, já que a todo o momento os professores a ele se referiram.

Em busca de maior validade na interpretação, foi realizada a quarta etapa de análise. Nesse momento, foram realizadas várias releituras de cada entrevista, para avaliar a homogeneidade interna das categorias até então definidas (BRAUN; CLARKE, 2006). Em seguida, com apoio do referencial teórico escolhido, foi analisada a coerência entre as categorias e os significados evidenciados. A participação direta dos três autores foi importante para possibilitar a revelação de sobreposições ou ambiguidades em algumas categorias, levando a uma reavaliação da interpretação construída. Concluindo a análise, as categorias foram definidas e nomeadas.

\section{PERCEPÇÕES DOS DOCENTES SOBRE O PLANO DE REFERÊNCIA}

A partir da análise das entrevistas realizadas foi possível perceber que apenas uma das professoras não é favorável à existência do Plano de Referência. Os outros 13 professores argumentam que a adoção do currículo comum pode dar unidade à prática pedagógica na rede de ensino. Pedro e Isadora, por exemplo, afirmam que é importante padronizar os conteúdos a serem ensinados durantes aulas, facilitando a mobilidade dos estudantes dentro da rede. Resultados semelhantes foram identificados por Seixas (2011) e Tenório (2012). Em consonância com Fernandes (2009), os professores Lucca e Sofia ressaltam que a existência de um documento norteador é especialmente importante para os professores iniciantes.

Uma característica importante do PR, elogiada por vários professores, foi a oportunidade de colaborar na elaboração da proposta, como é possível perceber no trecho da entrevista de Vinicius, apresentado a seguir:

[...] foi feito por profissionais da área, como mais um sinal positivo. Foram consultados os professores da rede. Então, eu acho que isso somou-se bastante. Foi baseado na realidade, na opinião dos professores, na necessidade dos professores, o que ajudou bastante. (Vinícius)

A participação dos professores na construção do currículo tem sido ampliada na rede, principalmente a partir da última reelaboração do $\mathrm{PR}$, quando os professores puderam opinar sobre o documento. $O$ envolvimento dos docentes pode ter influenciado na aceitação da proposta em Barueri. Para Sacristán (2000), a participação do professor permite que ele não se limite a consumir ou transmitir o currículo, mas seja estimulado também a interpretá-lo. Galian (2014) e Tenório (2012) afirmam que a colaboração do professor tem se tornado cada vez mais frequente. A impossibilidade de participar da construção da proposta curricular foi uma das críticas identificadas por Branquinho (2011), em estudo realizado com professores da rede estadual de São Paulo.

Outras características consideradas positivas da proposta de Barueri foram apresentadas pelos participantes, como sua adequação ao aluno, a diversificação dos temas propostos e a sequência construída. Interessante notar que estas características elogiadas são, na sequência da entrevista, criticadas por eles mesmos ou por outros professores, como veremos a seguir. 


\subsection{As críticas dos professores}

Embora os professores sejam favoráveis à existência do $P R$ e identifiquem pontos positivos na proposta, em seus relatos também é possível reconhecer uma insatisfação com 0 documento e com a forma como ele é implementado. Assim, uma série de críticas foram expressas pelos participantes, classificadas em três categorias expostas no quadro 1.

Quadro 1 - Críticas dos professores ao Plano de Referência

\begin{tabular}{|c|c|c|}
\hline Categorias & Subcategorias & Professores \\
\hline \multirow{2}{*}{$\begin{array}{l}\text { Relacionadas à concepção } \\
\text { que orienta a construção } \\
\text { do PR }\end{array}$} & Valorização excessiva do Esporte & Sofia e Juliana \\
\hline & $\begin{array}{l}\text { Incoerência entre os objetivos e os } \\
\text { conteúdos }\end{array}$ & Eduardo \\
\hline \multirow{5}{*}{$\begin{array}{l}\text { Relacionadas aos } \\
\text { conteúdos propostos }\end{array}$} & Repetição ou falta de diversificação & $\begin{array}{l}\text { Isis, Sofia, Paola, Juliana, Maria, Vitor, } \\
\text { Gilberto, Isadora, Mateus }\end{array}$ \\
\hline & $\begin{array}{l}\text { Sequência dos conteúdos } \\
\text { estabelecidos }\end{array}$ & $\begin{array}{l}\text { Pedro, Paola, Eduardo, Maria, Mateus, } \\
\text { Lucca }\end{array}$ \\
\hline & Inflexibilidade & Juliana, Lucca \\
\hline & $\begin{array}{l}\text { Inadequação às características dos } \\
\text { alunos }\end{array}$ & Isis, Hugo \\
\hline & $\begin{array}{l}\text { Falta de integração com outras áreas } \\
\text { do currículo }\end{array}$ & Eduardo, Vitor \\
\hline \multirow{6}{*}{$\begin{array}{l}\text { Relacionadas à } \\
\text { forma como o PR é } \\
\text { implementado }\end{array}$} & Forma como a avaliação é realizada & $\begin{array}{l}\text { Pedro, Sofia, Eduardo, Maria, Hugo, } \\
\text { Gilberto, Isadora, Mateus }\end{array}$ \\
\hline & Falta de recurso para implementar & $\begin{array}{l}\text { Pedro, Ísis, Paola, Eduardo, Maria, } \\
\text { Vítor, Hugo, Mateus }\end{array}$ \\
\hline & Preparação de tarefas burocráticas & $\begin{array}{l}\text { Vinícius, Ísis, Paola, Maria, Vítor, } \\
\text { Hugo, Mateus }\end{array}$ \\
\hline & Ausência de um material apostilado & Pedro, Sofia, Maria, Hugo, Gilberto \\
\hline & $\begin{array}{l}\text { Falta de investimento na formação } \\
\text { continuada }\end{array}$ & Ísis, Gilberto, Vitor \\
\hline & Organização escolar & Hugo \\
\hline
\end{tabular}

Fonte: elaborado pelos autores.

O primeiro bloco de críticas identificadas reúne os comentários dos professores sobre a concepção que fundamenta a proposta de Educação Física apresentada no PR. Para Sofia e Juliana, esta concepção valoriza excessivamente a prática esportiva. A análise do texto do PR permite concordar com a afirmação das professoras, pois a forma como os temas são apresentados no plano anual evidencia o predomínio de algumas modalidades esportivas no currículo. Exemplo desse predomínio aparece no $7^{\circ}$ ano, quando regras e habilidades de basquetebol, voleibol e futsal dominam $03^{\circ}$ e $04^{\circ}$ trimestres.

Ainda analisando a concepção que orienta o PR, o professor Eduardo destacou a incoerência entre a concepção defendida e a proposição de objetivos e conteúdos que aparecem no decorrer no plano. Essa incoerência também foi percebida em outras pesquisas (FRANÇOSO, 2011, TENÓRIO 2012). Na reformulação do PR foram realizadas alterações apenas no plano anual e na sequência dos conteúdos. Já a fundamentação teórica, parte do documento dedicada a apresentar a concepção que orienta sua elaboração, não sofreu 
qualquer alteração. É possível que a incoerência percebida pelo professor esteja relacionada com esse processo parcial de reformulação.

Os conteúdos propostos no PR também foram criticados pelos professores, constituindo a segunda categoria construída. Para nove deles, o plano apresenta repetição ou falta de diversificação de conteúdos. Eles argumentam que alguns temas merecem ocupar um maior espaço no currículo. Sofia e Gilberto criticam a falta de diversidade do PR, embora tenham elogiado essa característica em outro momento de suas entrevistas. Entretanto, ao analisar seus argumentos foi possível perceber que não há contradição em suas declarações. Ambos acreditam ser positiva a diversificação do plano, quando ele é comparado à prática tradicional da Educação Física. Mas, embora haja alguma diversificação no PR, os professores julgam que ela ainda é insuficiente.

A diversificação de temas e conteúdos da Educação Física tem sido valorizada pelos professores. Na percepção de alguns dos participantes nos estudos desenvolvidos por Branquinho (2011), Freitas (2011) e Barros (2014), a apresentação de temas variados tem estimulado o professor a procurar por conhecimento e formas de intervenção, possibilitando a aprendizagem sobre práticas culturais geralmente negligenciadas.

A inflexibilidade, a inadequação às características dos estudantes, a ausência de propostas interdisciplinares e a sequência de conteúdos estabelecida no plano foram outros pontos criticados pelos professores. Sobre a sequência dos conteúdos, é possível identificar que há percepções diferentes entre os professores. Assim, enquanto três deles elogiam a sequência proposta, seis a consideram inadequada e declaram que os conteúdos apresentados não se relacionam com os temas anteriores ou subsequentes, como explica Eduardo:

Dentro dos trimestres os conteúdos, eles não se relacionam, quase sempre são conteúdos diferentes, não há... um fio condutor entre os conteúdos que estão expostos lá para serem trabalhados no trimestre. $\mathrm{E}$ ao longo dos trimestres também tem pouca ou nenhuma relação, linearidade. $E$ entre os anos também isso se perde. (Eduardo)

À primeira vista, pode parecer incoerente a insatisfação dos professores com a concepção que orienta o PR e com a forma como os conteúdos são organizados, uma vez que eles se declaram favoráveis à existência de uma proposta curricular comum e tiveram oportunidade para participar da reformulação do documento. No entanto, consideramos essa insatisfação uma evidência de que a elaboração do currículo, ainda que aconteça de forma dialógica, é fruto de um processo bastante complexo, como explicitaram Sacristán (2000) e Santos (2002). Santos (2002) ressalta que uma proposta curricular é sempre fruto de disputas e embates. Para a autora, ainda que o grupo responsável por sua formulação compartilhe de concepções e objetivos comuns, os conflitos estarão sempre presentes. Assim, a construção coletiva do currículo não deve ser entendida como uma garantia de que o documento produzido atenda às expectativas de todos os professores.

Outro aspecto que merece ser analisado é que, embora os professores revelem ter sido convidados a contribuir com a reformulação do PR, a forma como essa contribuição se efetivou não chegou a ser questionada. Diferentes fatores podem ter influenciado o trabalho coletivo realizado (SANTOS, 2002), como a duração do processo, o número de encontros entre os professores, a forma como os encontros foram realizados, o nível de envolvimento dos professores, entre outros. É possível que a insatisfação identificada esteja relacionada à 
forma como o processo foi conduzido na rede. No estudo realizado por Liotti e Oliveira (2013), analisando a construção coletiva de uma proposta curricular de Biologia, os professores argumentam que, mesmo havendo a oportunidade para participar da elaboração do currículo, o documento criado não é expressão dessa participação. Assim, acreditamos que o processo de construção curricular adotado pode estar relacionado com a satisfação do professor com o currículo. A análise dessa relação pode motivar novos estudos.

Além da concepção e dos conteúdos propostos no PR, os professores avaliaram também a forma como ele tem sido implementado. Identificamos nessas críticas sete diferentes subcategorias (Quadro 1). A interferência da organização escolar sobre as aulas de Educação Física, como a realização de eventos que geram alterações no planejamento do professor, foi dificuldade descrita por um professor. Ísis, Vítor e Gilberto criticaram a falta de investimento na formação continuada na rede. Os professores ressaltam a importância de dialogar com os pares sobre suas experiências, para que possam construir juntos formas de enfrentar dificuldades. Resultados semelhantes foram descritos por Branquinho (2011), Seixas (2012), Lagoeiro (2012) e Tenório (2012).

A carência de recursos materiais para a construção das aulas sobre temas apresentados no PR foi relatada por alguns professores e identificada também nos trabalhos de Maldonado (2012), Marques (2014) e Rocha (2014). Também relacionada à falta de material didático está a crítica dos professores à ausência de um material apostilado, específico para utilização na Educação Física. Para os participantes, esse material facilitaria o trabalho, dinamizando 0 tempo de algumas atividades, como leitura e discussão de textos com os alunos. Marques (2014) encontrou manifestação semelhante entre os professores de um município do interior paulista. No estudo realizado por Rocha (2014), alguns professores elogiaram a elaboração dos cadernos do professor e do aluno, por apresentarem sugestões e orientações específicas para o ensino da Educação Física.

No entanto, a criação de um material apostilado não é consenso entre os professores participantes. Mateus e Lucca são contrários a essa ideia. Destacamos a seguir trecho da entrevista de Mateus, que se mostra preocupado com uma possível perda de autonomia:

[...] aqui, pelo menos, a gente conversa... não preciso nem comunicar nada, tem uma autonomia para o professor, e pelo menos... na minha área. Então, eu posso trazer material, não tem problema nenhum. De repente, se criar o "caderno do aluno"... Aí vai ter que seguir... entendeu? Eu acho que do jeito que está é menos pior... (Mateus).

No argumento apresentado por Mateus é possível perceber o temor de que o material apostilado possa limitar sua prática pedagógica, uma vez que ele define um roteiro a ser seguido pelo professor. O mesmo poder limitador pode ser exercido por outras duas estratégias utilizadas na implementação do PR e criticadas pelos professores: a exigência de tarefas burocráticas e o sistema de avaliação adotado.

Grande parte dos entrevistados considera excessiva a exigência de planos e relatórios diversos (plano anual, planejamento mensal, diários e portfólios). Os professores argumentam que essas são tarefas burocráticas, que não contribuem para a qualidade do trabalho realizado. Além disso, eles declaram que o volume de tarefas a serem executadas lhes ocupa o tempo que poderia ser utilizado na melhor elaboração das aulas e do material didático. A mesma percepção foi identificada por Lagoeiro (2012). 
Nos documentos mencionados são descritas as atividades planejadas, como foram realizadas e qual a avaliação dos professores a respeito de sua prática pedagógica. Portanto, a partir dos documentos elaborados, é possível identificar se o professor está seguindo as determinações expressas no PR. Os professores percebem essa relação e entendem as tarefas realizadas como instrumentos utilizados pelos gestores para controlar a prática pedagógica implementada. Talvez por isso, alguns deles optem por elaborar seus planos, mensários e diários sem apresentar o que realmente realizam nas aulas, como relata Isis:

Inclusive, você me desculpa, tem professor até que coloca aquilo que não faz. Então, por isso eu acho totalmente desnecessário. Totalmente! Então eu não vejo necessidade nenhuma de toda essa papelada que a gente tem que fazer. (Isis).

A exigência de relatórios e planos parece estar diretamente relacionada com a implementação do PR, tendo como objetivos assegurar que o professor construa uma prática planejada e acompanhar de perto o trabalho por ele realizado. Portanto, é um mecanismo de controle do currículo e das práticas docentes, a partir do qual se tenta garantir que o currículo implementado pelo professor (currículo real) se aproxime do proposto no PR (currículo oficial). Outro mecanismo utilizado com a mesma finalidade é a avaliação em larga escala (BARRETO, 2012).

Os professores entrevistados criticaram a forma como a avaliação é realizada na rede, que nem sempre é elaborada em conformidade com o PR e, por vezes, é considerada recurso para inibir possíveis alterações na sequência de conteúdos, definida oficialmente. Além disso, eles afirmam que o tempo nem sempre é suficiente para que os conteúdos sejam tratados adequadamente e julgam negativo o fato da avaliação escolar se refletir no bônus produtividade a ser recebido pelo professor.

A avaliação é padronizada em toda a rede. Cada professor deve utilizar os seguintes instrumentos: avaliações contínuas, com peso 2; avaliações mensais, com peso 2; e avaliação trimestral, com peso 1. A avaliação trimestral é elaborada pela Secretaria da Educação, sendo constituída por questões sobre os conteúdos definidos no PR. Elas são realizadas em todas as escolas, durante três dias subsequentes, definidos no calendário anual da rede. A avaliação de Educação Física ocorre sempre no segundo dia, sendo constituída por cinco questões.

Segundo Bonamino e Souza (2012), esse tipo de avaliação é parte de um sistema de avaliação que integra a política educacional brasileira adotada a partir da década de 1980. Como explicam os autores, a primeira iniciativa de avaliação geral no país foi o Sistema Nacional de Avaliação da Educação Básica (SAEB), criado em 1991. Ele faz parte da primeira geração de avaliação em larga escala, tendo por objetivo construir um diagnóstico e acompanhar da qualidade da educação brasileira. Aos poucos, a política de avaliação passou a ser considerada instrumento para melhoria da qualidade da educação básica, com a responsabilização daqueles que devem se encarregar de produzir essa qualidade, entre eles estão professores e gestores (NOVAES, 2009). Nesse momento, surgem as políticas de avaliação de segunda e terceira gerações (BONAMINO; SOUZA, 2012). A avaliação trimestral realizada na rede municipal de Barueri é política de avaliação de terceira geração, caracterizada pela "responsabilização baseada em consequências simbólicas e materiais" (BONAMINO; SOUZA, 2012, p. 383), com o objetivo estimular o empenho do professor.

Segundo Bonamino e Sousa (2012, p. 386) uma consequência da utilização de avaliações centralizadas tem sido a preocupação excessiva de diretores e professores em 
preparar os alunos para os testes, "[...] levando a um estreitamento do currículo escolar". Essa preocupação também é expressa pelos professores entrevistados, como é possível observar no relato apresentado a seguir: "[...] os alunos fazem a prova daquele conteúdo que tem no currículo. Então, se eles forem mal, se todo mundo for mal, quer dizer que eu não fui bem com eles, não é verdade? Então, a gente tem que cumprir" (Vitor).

Além de diagnosticar o desempenho dos alunos e a qualidade da educação, políticas de avaliação orientam a formulação do planejamento e, consequentemente, influenciam a construção do currículo. Nessa perspectiva, a adoção dos sistemas de avaliação, construídos sobre o argumento da melhora da qualidade do ensino e da necessidade de atender aos padrões de desempenho internacionais, tem se refletido na elaboração de propostas curriculares (BARRETO, 2012), como a adotada na rede municipal de Barueri.

A influência dessa política sobre a prática pedagógica do professor foi percebida no presente estudo. Durante a análise das entrevistas, identificamos que as tarefas burocráticas e o sistema de avaliação em larga escala, questionados por alguns professores, interferem nas escolhas que eles fazem. Isso aparece, por exemplo, no relato de Eduardo:

Há uma preocupação dos docentes em implementar a proposta porque ela é cobrada nas avaliações trimestrais... É o que pode engessar a prática dos professores... você vai acabar implementando esses conteúdos porque os alunos serão avaliados por ele.

A partir do exposto, se explicita a insatisfação dos professores com a forma como o PR foi implementado. Em suas declarações, é possível perceber que eles não foram consultados sobre essa implementação. Assim, voltando a analisar o processo de participação deles na construção do PR, podemos presumir que ela foi limitada à discussão sobre o conteúdo do PR. Um processo democrático deveria garantir aos seus elaboradores a participação em todas as etapas de construção do plano. Uma dessas etapas envolve as decisões sobre as formas de implementação.

\subsection{As relações entre o currículo oficial e o real}

Como explica Freitas (2011), existe uma expectativa de que o envolvimento do professor na elaboração curricular resulte em adoção às determinações que ele ajudou a construir. Inicialmente, pode parecer que essa expectativa se confirma no presente estudo, pois os professores declaram aderir ao PR e, ao citarem trechos ou sequências de conteúdos, demonstram conhecer o documento em detalhes. Desta forma, se configura a adoção do currículo oficial, comprovando que ele configura a ação docente, como afirma Sacristán (2000). No entanto, a adoção dos professores não é total, já que apenas uma professora declarou não realizar alterações no Plano. Os outros 13 participantes afirmam remodelar o currículo oficial, adaptando-o às características dos estudantes ou à concepção de Educação Física que orienta sua intervenção.

Paola, Eduardo, Maria e outros nove colegas declararam inserir temas não apresentados no PR. Outras formas de ação dos professores no currículo, manifestas durante a entrevista, foram a mudança da ordem dos conteúdos ou a exclusão de alguns temas propostos. Os professores Maria e Hugo modificam a ordem para adequar os conteúdos à sua prática pedagógica, como exemplificado a seguir no trecho da professora: 
Eu troco de ordem, se eu acho que, por exemplo, em Língua Portuguesa, Danças folclóricas é no segundo trimestre, ou Artes também, já dá pra fazer um trabalho junto. É segundo trimestre, no meu tá no terceiro, eu puxo pro segundo trimestre. Então, eu faço essas alterações. (Maria).

Ísis e Hugo declararam excluir conteúdos que consideram inadequados aos alunos. Ísis argumenta que essas mudanças também são influenciadas pelo tempo disponível para o tratamento de alguns temas. Já o professor Hugo explica que exclui alguns conteúdos, quando eles estão desconectados das necessidades dos estudantes ou quando a escola não fornece os recursos materiais que ele julga serem necessários. Essas alterações relatadas pelos professores podem exemplificar como eles agem sobre o currículo e continuam a reconstruí-lo cotidianamente (SACRISTÁN, 2000).

\subsection{Tensões e conflitos na construção do currículo}

A análise da adoção do PR pelos professores, a partir de seus relatos, nos permitiu compreender que as concepções e práticas propostas no documento não parecem representálos integralmente, ainda que eles tenham participado de sua elaboração. Isso acontece porque esses professores trazem consigo diferentes concepções de Educação Física. Será possível estabelecer um diálogo e contemplar todas essas concepções numa única proposta curricular? Como argumenta Santos (2002, p. 351),

[...] um currículo, mesmo quando elaborado por um grupo que compartilha de ideias comuns, representa sempre um consenso precário em torno de algumas ideias. Esse consenso é precário na medida em que, no processo de negociação para as definições curriculares, há concessões e intransigências, grupos que cedem ou recuam, grupos que são silenciados, porque não conseguem adesão a suas propostas e assim por diante.

Portanto, se o PR é marcado pela hegemonia do esporte e pela aprendizagem de técnicas e habilidades motoras, como argumentam alguns dos entrevistados, é porque há professores que defendem esta concepção de Educação Física e conseguiram ter sua perspectiva contemplada, sendo mais bem sucedidos nas disputas de poder travadas durante a formulação do plano. 0 posicionamento contrário de alguns evidencia que as disputas continuam e são marcadas por diferentes interesses. Assim, como explicam Sacristán (2000) e Santos (2002), a elaboração de um currículo é fruto de um processo complexo e conflituoso.

Outro conflito percebido nas declarações dos professores foi o anseio, simultâneo, pela padronização e pelo respeito aos interesses individuais. Assim, é possível perceber que eles defendem a existência de um currículo comum, que permita trazer coesão ao trabalho realizado na rede, como podemos perceber nos trechos destacados a seguir:

Eu gosto sim, por ter uma sequência. Ter algo, embora, às vezes não seja seguida, né, mas eu acho que isso me ajuda a ter uma organização melhor. (Maria).

Eu acho legal ter essa proposta fechada, porque se um aluno sai de uma escola e vai pra outra, ele vai acabar pegando basicamente o mesmo conteúdo lá. (Pedro).

Para alguns deles, a homogeneidade é tão importante que chegam a defender a utilização de outros mecanismos para estimular os colegas a seguirem as determinações curriculares oficiais, como a criação de material apostilado. Essa ideia pode ser percebida nas declarações de Sofia, apresentadas a seguir. 
[...] Porque, quando se trata de pessoas, cada uma vai trabalhar do seu jeito, do seu modo. Quando você tem uma apostila, você sabe que vai ter que trabalhar aquilo, e é claro que você pode trabalhar aquilo de maneiras diferentes. Porém, ali 0 aluno ele tem um subsídio que se ele precisar estudar para uma prova, vai vir referente àquilo ele tem de onde tirar. E você conseguiu fazer o seu trabalho. Coisa que aqui eu acho muito dif́cil porque cada um vai trabalhar de um jeito, cada um trabalha de uma forma e acaba ficando um pouco jogado. (Sofia).

No entanto, ainda que se entusiasmem pela uniformidade, os professores condenam a inflexibilidade criada pelo PR e controlada com a exigência de tarefas burocráticas e do sistema de avaliação em larga escala. Nessa medida, reivindicam a possibilidade de amoldar seu planejamento às suas concepções e/ou às características, necessidades e preferências de seus estudantes. Exemplos desse desejo pela flexibilização do PR aparecem nos trechos destacados a seguir.

Eu tornaria ele mais flexível. Então, ao invés de colocar, por exemplo, primeiro trimestre é Futsal, eu colocaria modalidades coletivas. Então, a pessoa pode, por mais que acaba trazendo um pouco mais pra subjetividade do professor, que se 0 professor prefere basquete ele vai acabar trabalhando basquete. (Lucca).

É, eu acho que de vez em quando tem umas coisas que estão no lugar errado, tem alguns conteúdos do terceiro e quarto ano que eram pra estar no sexto ano. (Pedro).

Como explica Sacristán (2000), o currículo comum procura unificar, homogeneizar o trabalho na escola, priorizando elementos culturais. Consequentemente, essa padronização pode desconsiderar as diferenças culturais e sociais presentes na escola e fora dela. É possível construir uma proposta curricular que traga coesão e, ao mesmo tempo, permita alguma flexibilidade ao trabalho pedagógico? Encontrar esse equilíbrio entre os interesses coletivos e individuais é o desafio daqueles que constroem o currículo. Para Apple (1994), embora seja possível apresentar argumentos coerentes para defender a adoção de um currículo comum e de uma decorrente política de avaliação nacional, é preciso analisar o contexto que tem gerado a defesa dessa política e a quem ela beneficia. Para o autor, o risco envolvido nessa adoção é muito alto e, por isso, argumenta que:

Em sociedades complexas como a nossa, marcadas pela distribuição desigual de poder, o único tipo de "coesão" possível é aquele em que reconheçamos abertamente diferenças e desigualdades. 0 currículo, dessa forma, não deve ser apresentado como "objetivo". Deve, ao contrário, subjetivar-se constantemente. (APPLE, 1994, p. 76).

Contudo, Apple (1994) também reconhece que o currículo comum pode impulsionar o diálogo sobre os saberes que o constituirão. Poderemos, no futuro, avaliar a coerência das ideias defendidas pelo autor com a experiência da construção da Base Nacional Curricular Comum (BRASIL, 2016) em nosso país.

\section{CONSIDERAÇÕES FINAIS}

O processo de criação de propostas curriculares comuns tem exigido de professores e pesquisadores a reflexão sobre a construção do currículo da Educação Física. Por conseguinte, aquele professor que tinha a liberdade e a responsabilidade de construir seu currículo, 
individualmente ou em consonância com o projeto político pedagógico da escola, hoje precisa aprender a estruturar uma prática pedagógica adequada ao currículo oficial, construído com ou sem sua colaboração. Este estudo foi realizado com o objetivo de conhecer como esse professor percebe o desafio que lhe é apresentado.

Como demonstrado em alguns estudos utilizados nesta pesquisa, percebemos que a construção curricular é marcada por tensões e conflitos entre as diferentes concepções apresentadas por professores da rede. Esses professores são favoráveis à existência de uma proposta curricular comum para o município de Barueri e valorizam a oportunidade de participar de sua construção. Ainda assim, identificam uma série de inconsistências no currículo e, principalmente, na forma como ele tem sido implementado na rede. Embora tenham contribuído para a produção do projeto, não julgam que suas expectativas tenham sido atendidas, e anseiam por flexibilizar sua implementação. Deste modo, eles declaram elaborar uma prática que considera o Plano de Referência, mas que também o reconstrói.

A complexidade envolvida no delineamento do currículo foi percebida, demonstrando que o professor não é apenas influenciado pelo currículo oficial, mas também o transforma. É possível perceber essa transformação quando se constata que os participantes declaram alterar constantemente o currículo oficial, incluindo, excluindo ou modificando a ordem dos conteúdos e habilidades propostos. Assim, a inter-relação entre as dimensões do currículo torna-se explícita.

Se o PR não atende às expectativas de alguns dos professores participantes é porque a construção do currículo, seja ou não coletiva, é marcada por embates sobre as concepções e os objetivos educacionais daqueles que dela participam. Uma série de interesses pode interferir nesta construção e o resultado não será consensual. Nessa perspectiva, acreditamos que novos estudos devem ser realizados para acompanhar a construção curricular coletiva na Educação Física, possibilitando compreender como o professor se envolve nessa construção, além de permitir identificar os diferentes interesses de seus elaboradores e os fatores geradores de conflitos.

\section{REFERÊNCIAS}

APPLE, Michael. A Política do conhecimento oficial: faz sentido a ideia de um currículo nacional? In: MOREIRA, Antônio Flávio Barbosa; SILVA, Tomaz Tadeu da (Org.). Currículo, cultura e sociedade. São Paulo: Cortez, 1994. p. 59-91.

ARRUDA, Leomar Cardoso. Organização curricular da educação física no ensino fundamental em Catalão-GO: análise a partir dos discursos dos professores. 2014. 184f. Dissertação (Mestrado em Educação Física) - Universidade Federal do Triângulo Mineiro, Uberaba, 2014.

BARRETO, Elba Siqueira de Sá. Políticas de currículo e avaliação e políticas docentes. Cadernos de Pesquisa, v. 42, n. 147, p. 738-753, set./dez. 2012.

BARROS, André Minuzzo de. Os conteúdos e a prática pedagógica de educação física: análise do currículo do Estado de São Paulo. 2014. 193f. Tese (Doutorado em Desenvolvimento Humano e Tecnologias) - Instituto de Biociências, Universidade Estadual Paulista, Rio Claro, 2014. 
BARUERI. Secretaria da Educação. Plano de referência para a educação básica do município de Barueri. Barueri: Traço, 2015.

BOGDAN, Robert; BIKLEN, Sari. Investigação qualitativa em educação: uma introdução à teoria e aos métodos. Porto: Porto, 1994.

BONAMINO, Alicia; SOUSA, Sandra Zákia. Três gerações de avaliação da educação básica no Brasil: interfaces com o currículo da/na escola. Educação e Pesquisa, v. 38, n. 2, p. 373-388, abr.jun. 2012.

BRANQUINHO, Rubens dos Santos. Currículos apostilados: o professor de educação física da escola pública do estado de São Paulo frente ao novo paradigma educacional. 2011. 179f. Dissertação (Mestrado em Educação) - Pontifícia Universidade Católica de São Paulo, São Paulo, 2011.

BRASIL. Lei n.ำ 9.394 de 20 de 23 de dezembro de 1996. Estabelece as diretrizes e bases da educação nacional. Diário Oficial da União, Brasília, Seção 1, p. 27833-27841, 23 dez. 1996.

BRASIL. Ministério da Educação. Base nacional curricular comum: proposta preliminar. 2. versão rev. Brasília: 2016. Disponível em: $<$ http://basenacionalcomum.mec.gov.br/documentos/bncc-2versao. revista.pdf>. Acesso em: 15 maio 2016.

BRASIL. Secretaria de Educação Fundamental. Parâmetros curriculares nacionais: Educação Física. Brasília: MEC/SEF, 1997. Disponível em: <http://portal.mec.gov.br/seb/arquivos/pdf/livro07. pdf>. Acesso em: 22 abr. 2015.

BRAUN, Virginia; CLARKE, Victoria. Using thematic analysis in psychology. Qualitative Research in Psychology, v. 3, n. 2, p. 77-101, jul. 2006.

BRINKMANN, Svend. Could interviews be epistemic?: An alternative to qualitative opinion polling. Qualitative Inquiry, v. 13, n. 8, p. 1116-1138, dec. 2007.

CAMPOS, Claudinei José Gomes. Método de análise de conteúdo: ferramenta para a análise de dados qualitativos no campo de saúde. Revista Brasileira de Enfermagem, v. 57, n. 5, p. 611-614, set./out. 2004.

CASTELLANI, Rafael Moreno. Nova proposta curricular do estado de São Paulo: limites e virtudes. Conexões, v. 11, n.1, p. 235ם251, 2013.

FRANÇOSO, Saulo. Cruzando fronteiras curriculares: a educação física sob o enfoque cultural na ótica de docentes de escolas municipais de São Paulo. 2011. 153f. Dissertação (Mestrado em Educação) - Pontifícia Universidade Católica, São Paulo, 2011.

FERNANDES, Anoel. A proposta pedagógica para a educação física escolar nas séries iniciais da rede pública estadual paulista: as manifestações dos professores. 2009. 136f. Dissertação (Mestrado em Educação). Pontifícia Universidade Católica de São Paulo. São Paulo, 2009.

FREITAS, Tatiana Pereira. Autonomia e identidade profissional de professores de educação física diante da proposta curricular do estado de São Paulo. 2011. 175f. Dissertação (Mestrado em Educação) - Pontifícia Universidade Católica de São Paulo, São Paulo, 2011.

GALIAN, Claudia Valentina Assumpção. Os PCN e a elaboração de propostas curriculares no Brasil. Cadernos de Pesquisa, v. 44, p. 648-669, 2014.

GODOY, Arilda Schmidt. Introdução à pesquisa qualitativa e suas possibilidades. Revista de

Administração de Empresas, v. 35, n. 2, p. 57-63, mar./abr. 1995. 
GUNTHER, Maria Cecilia Camargo. A prática pedagógica dos professores de Educação Física e o currículo organizado por ciclos: um estudo na Rede Municipal de Ensino de Porto Alegre. Tese (Doutorado) - Universidade Federal do Rio Grande do Sul, Porto Alegre, 2006.

KVALE, Steiner. Doing interviews. Thousand Oaks: Sage, 2007.

LAGOEIRO, João Bosco Mussolin. 0 currículo de educação física na rede estadual paulista: concepções dos professores dos anos iniciais do ensino fundamental. 2012. 183f. Dissertação (Mestrado) - Centro Universitário Moura Lacerda, Ribeirão Preto, 2012.

LIOTTI, Luciane Cortiano; OLIVEIRA, Odisséa Boaventura. Produção coletiva de currículo: um caminho para sua implantação. Revista e-Curriculum, n.11, v. 3, p. 863-888, set./dez. 2013.

MALDONADO, Daniel Teixeira. Implementação da proposta curricular de educação física do município de São Paulo. 2012. 344f. Dissertação (Mestrado em Educação Física) - Universidade São Judas Tadeu, São Paulo, 2012.

MARQUES, Marcos Vinicius. 0 processo de configuração curricular: uma análise da compreensão de professores de educação física das séries iniciais do ensino fundamental. 2014. 119f. Dissertação (Mestrado) - Universidade Estadual Paulista, Rio Claro, 2014.

NOVAES, Luiz Carlos. Os impactos da política educacional paulista na prática docente e na organização do trabalho pedagógico nas escolas estaduais paulistas na perspectiva dos professores. Jornal de Políticas Educacionais, n. 5, p. 13-26, jan.jjun. 2009.

ROCHA, Robson Luiz Franco da. A prática pedagógica de educação física a partir do currículo do estado de São Paulo. 2014. 187f. Dissertação (Mestrado) - Universidade Estadual de Campinas, Campinas, 2014.

SACRISTÁN, Jean Gimeno. 0 currículo: uma reflexão sobre a prática. Porto Alegre: Artmed, 2000.

SACRISTÁN, Jean Gimeno. O que significa o currículo? In: SACRISTÁN, Jean Gimeno (Org.).

Saberes e incertezas sobre o currículo. Porto Alegre: Penso, 2013. p. 16-37.

SAMPAIO, Maria das Mercês F. (Coord.) Relatório de análise de propostas curriculares de ensino fundamental e médio. São Paulo: MEC, 2010. Disponível em: <http://portal.mec.gov.br/ index.php?option=com docman\&view=download\&alias=7013-relatorio-seb-anlisepropostas-efem\&category slug=novembro-2010-pdf\&ltemid=30192>. Acesso em: 10 abr. 2016.

SANTOS, Lucíola Licínio de C. P. Políticas públicas para o ensino fundamental: Parâmetros Curriculares Nacionais e Sistema Nacional De Avaliação (SAEB). Educação e Sociedade, v. 23, n. 80, p. 346-367, set. 2002.

SÃO PAULO (SP). Secretaria Municipal de Educação. Diretoria de Orientação Técnica.

Orientações curriculares e proposição de expectativas de aprendizagem para o Ensino Fundamental: ciclo I. Secretaria Municipal de Educação. São Paulo: SME/DOT, 2007. Disponível em: <https://www.escrevendoofuturo.org.br/EscrevendoFuturo/arquivos/1077/OrientaCurriculares ExpectativasAprendizagem EnsFnd ciclol.pdf>. Acesso em: 10 abr. 2016.

SÃO PAULO. Secretaria Estadual de Educação. Currículo do Estado de São Paulo: Linguagens, códigos e suas tecnologias/Secretaria da Educação. São Paulo: SEE, 2008. Disponível em: <http:// www.educacao.sp.gov.br/curriculo>. Acesso em: 10 abr. 2016.

SEIXAS, Marcos Vinicius. 0 currículo prescrito de educação física na concepção dos docentes da rede estadual paulista. 2011. 146f. Dissertação (Mestrado) - Centro Universitário Moura Lacerda, Ribeirão Preto, 2011. 
SOARES, Carmem Lúcia et al. Metodologia do ensino de educação física. São Paulo: Cortez, 1992.

TENÓRIO, Kadja Michele Ramos. 0 diálogo entre o currículo oficial e real na implementação de uma proposta curricular para a educação física escolar: um estudo de caso. 2012. 146f. Dissertação (Mestrado) - Universidade de Pernambuco/Universidade Federal da Paraíba, Recife, 2012. 